\title{
Process Optimization of Bimetallic Composite Pipe by Investment Casting Based on ProCAST
}

\author{
Tang Haiyan, Li Jingshe, Yang Hongbo \\ State Key Laboratory of Advanced Metallurgy \\ University of Science and Technology Beijing \\ Beijing 100083, China
}

\begin{abstract}
The casting and solidification process of the bimetallic composite pipe were simulated by ProCAST software aiming at the misrun defect in the pipe. The causes of defect were analyzed from the factors of the pouring temperature, pouring time, preheating temperature of mold and the height of sprue. Reasonable improvements were presented based on the simulation results. Industrial tests showed that misrun defect disappeared after the process was improved, which in turn verified the effectiveness and reliability of simulation results.
\end{abstract}

Keywords-Bimetallic composite pipe; Investment casting; Mold filling; Solidification; Misrun defect

\section{INTRODUCTION}

Pipe fittings are widely used in petroleum, chemical, automobile, construction and other industries. With the development of these industries, increasing demands are put forward on their quality and performance. Not only high hardness and strength but also good corrosion resistance and wear resistance are required, especially for those working in the harsh environment. Most of pipe fittings used nowadays is made of single material, whose overall performance is improved by adding rare and precious metals such as $\mathrm{Ti}, \mathrm{Nb}$ and V. Due to the limit resources for these metals, the costs of pipe fittings have to be increased.

Bimetallic composite pipe is composed of two different metal materials. The close combination between metal layers achieves the excellent performance of pipe fittings and the complementary advantages of two metals, Along with low cost, it can replace the pipe fitting composed of single material.

Currently, the research on bimetallic composite pipe fitting produced by investment casting is less. Misrun defects occurred to the bottom of the pipe fitting produced with investment casting method in a factory of China, which seriously affected the quality of the product.

With the development of computer, numerical simulation of casting process has achieved a major breakthrough. Defects of castings could be predicted by simulating the mold filling and solidification process, further the casting process could be optimized, the trial period shortened and production costs reduced [1 4]. So, the mold filling and solidification process of bimetallic composite pipe were simulated by ProCAST software in the paper to find out the causes of misrun defects and then to propose targeted solutions.

\section{INDUSTRIAL TRIAL OF A BIMETALLIC COMPOSITE PIPE}

The selected pipe materials were $16 \mathrm{Mn}$ for the outer layer and 304 stainless steel for the inner layer. The bending angle of pipe was $90^{\circ}$. The chemical compositions of $16 \mathrm{Mn}$ and 304 were in Table I. First, the outer layer metal was cast and grinded, then EPS white mold was put into the bending pipe and the shell was made by sand. After baked at 70 degree Centigrade and roasted at 700 degree Centigrade, 1700 degree Centigrade of stainless steel liquid from the intermediate frequency furnace was poured into the mold within 17 seconds, and then cooled to the room temperature.

The bimetallic bending pipe produced was shown in Figure 1. As seen, misrun defect appeared in the bottom of the inner layer.

\section{NUMERICAL SIMULATION OF CASTING PROCESS OF BIMETALLIC BENDING PIPE}

\section{A. Establishment of model and verification}

ProCAST developed by the USE Company in USA is an internationally recognized casting simulation software with high precision. Based on numerical calculation of finite element (FEM) and comprehensive solution, it can simulate the flow of liquid during casting, display misrun, cold shut, and residual stress and deformation, and accurately predict the shrinkage hole $[2,3]$.

The liquidus and solidus temperatures of 304 stainless steel were $1438^{\circ} \mathrm{C}$ and $1381^{\circ} \mathrm{C}$, respectively. The liquidus and solidus temperatures of $16 \mathrm{Mn}$ were $1513^{\circ} \mathrm{C}$ and $1469^{\circ} \mathrm{C}$, respectively. The convection heat transfer coefficient between the shell and air was taken $8 \mathrm{w} /(\mathrm{m} 2 \cdot \mathrm{K})$, and emissivity 0.85 .

The pouring temperature of 304 stainless steel liquid was $1700^{\circ} \mathrm{C}$, preheating temperature of mold $700^{\circ} \mathrm{C}$, gravity direction straight down, pouring time $17 \mathrm{~s}$, and casting speed $0.921 \mathrm{~kg} / \mathrm{s}$. The temperature field distribution of the filling and solidification process of the bimetallic bending pipe obtained under the above conditions is shown in Figure 2. In order to facilitate the observation, the model of the outer layer was hidden.

It is seen from the figure that the filling is just finished at the moment of $17 \mathrm{~s}$ and misrun defect appears at the bottom 
of the pipe signed with letter A. And, the area of defect is basically constant with the solidification time increasing. This is in agreement with the industrial trial, which shows the boundary condition of model was set reasonably.

The cooling of 304 steel liquid is very quick because it is only $5 \mathrm{~mm}$ thick. As seen in Figure.2, the temperature at the bottom of mold is only $1219^{\circ} \mathrm{C}$ at the moment of $17 \mathrm{~s}$, lowering $481^{\circ} \mathrm{C}$ than the temperature at the gate. And, the temperature of a large part of the bottom is lower than solidus temperature $\left(1381^{\circ} \mathrm{C}\right)$ of 304 stainless steel, which results in the steel liquid having no flowing capacity and unable to fill in the hole, further appearing misrun defect.

\section{B. The impact factors of misrun defects}

To avoid the appearance of misrun defect, simulations were done considering the pouring temperature, pouring time, preheating temperature of mold, and the height of pressure head.

1) The effect of pouring temperature:

The pouring temperatures were set at 1600, 1650, 1700 and $1750{ }^{\circ} \mathrm{C}$, while the other parameters kept constant. The simulation results of the shrinkage rate of a casting are shown in Figure 3. It is seen that misrun defect is significantly improved with the pouring temperature increasing. When the temperature reaches $1750^{\circ} \mathrm{C}$, the defect disappears. However, "burn-through" phenomenon will occur in industrial production if the casting temperature is too high, so it is unrealistic to improve defect simply by increasing the pouring temperature.

\section{2) The effect of pouring time:}

The pouring time was set from $17 \mathrm{~s}$ to $5 \mathrm{~s}$, while the other parameters kept constant. Simulation results show that misrun defect of the casting is improved with the pouring time shortening. The defect disappears when the pouring time is shortened to $10 \mathrm{~s}$. This is because, on one hand, the heat transfer time between molten steel and environment shortens with the decrease of pouring time. On the other hand, the kinetic energy of molten steel increases with filling speed increasing, which will increase the flowing ability of molten steel and improve misrun defect.

3) The effect of mold preheating temperature.

Setting the preheating temperature $600^{\circ} \mathrm{C}, 700^{\circ} \mathrm{C}, 800^{\circ} \mathrm{C}$ and $900^{\circ} \mathrm{C}$, other parameters kept unchanged. Simulation results show that the casting defect is significantly improved with the preheating temperature increasing, and the defect disappears at the preheating temperature of $800^{\circ} \mathrm{C}$.

4) The effect of pressure head of casting.

Setting the height of pressure head of casting from $100 \mathrm{~mm}$ (the height of industrial production) to $220 \mathrm{~mm}$, other parameters kept unchanged. Simulation results show that misrun defect won't disappear in the range of the heights. Defect area decreases with the height increasing in the range of $100 \mathrm{~mm}$ to $180 \mathrm{~mm}$. On the contrary, it increases in the range of $180 \mathrm{~mm}$ to $220 \mathrm{~mm}$.

It is interpreted as that the filling of molten steel is a process which gravitational potential energy of molten steel is converted to kinetic energy. As the height of pressure head increases, gravitational potential energy of molten steel increases, then kinetic energy correspondingly increases. So, the flowing capacity of molten steel increases, further misrun defect is improved.

On the other hand, the filling of molten steel is also a cooling process with strong heat exchange between the molten steel and surrounding environment. As the height of sprue increases, the heat loss of molten steel will increase, which is unfavorable for the improvement of defect.

The positive effect dominates when the height of sprue is from $100 \mathrm{~mm}$ to $180 \mathrm{~mm}$, while the negative effect dominates when sprue is from $180 \mathrm{~mm}$ to $220 \mathrm{~mm}$.

\section{INDUSTRIAL IMPROVEMENTS}

Based on the simulation results, some improvements were done on the site. The mold preheating temperature was increased from $700^{\circ} \mathrm{C}$ to $750^{\circ} \mathrm{C}$, the horizontal runner of outer side was widened from $30 \mathrm{~mm}$ to $40 \mathrm{~mm}$, and the height of riser was increased from $100 \mathrm{~mm}$ to $135 \mathrm{~mm}$. There was no misrun defect in the produced bimetallic composite pipe. As a result, numerical simulation can guide the practice well.

\section{CONCLUSIONS}

(1) The filling and solidification process of bimetallic composite pipe were simulated based on ProCAST software, and misrun defect was predicted. The simulation results were in agreement with the industrial experiment.

(2) The causes of misrun defects and affecting factors were analyzed. The results showed that the defect could be improved by increasing the preheating temperature of mold and pouring temperature, shortening casting time, and broadening the outside runner.

(3) The industrial improvements were done according to the simulation results and the desired effect was achieved.

\section{REFERENCES}

[1] YAN Kangmin, TANG Jianxin. Process Optimization of LFC Casting Grinding Balls Based on ProCAST [J]. Hot Working Technology, 2010, 39(7): 49 52.

[2] Pan Liwen, Gao Yong, Gao Wenli, Hu Zhiliu, Zheng Lijing, Zhang $\mathrm{Hu}$. Prediction of Shrinkage Porosity (Hole) in TiAl Based Alloy Blade and Its Processing Optimization Based on the Procast [J]. Special Casting \& Nonferrous Alloys, 2010, 30(6): 504 509.

[3] Wang Xu, Zhao Yutao, Su Dawei. Optimization Design of Riser of Motorcycle Wheels by Metal Mold Gravity Casting Based on ProCAST (in Chinese). Casting, 2009, 58(7): 700 703.

[4] Application of ProCAST in the Optimization of Casting Process (in Chinese). Hot Working Technology, 2006, 35(1): 52 53. 
TABLE I. REQUIRED CHEMICAL COMPOSITIONS FOR OUTER AND INNER LAYERS (WT\%)

\begin{tabular}{|c|c|c|c|c|c|c|c|}
\hline Item & $\mathrm{C}$ & $\mathrm{Si}$ & $\mathrm{Mn}$ & $\mathrm{S}$ & $\mathrm{P}$ & $\mathrm{Cr}$ & $\mathrm{Ni}$ \\
\hline \multirow{2}{*}{$16 \mathrm{Mn}$} & $\begin{array}{c}0.13 \sim \\
0.19\end{array}$ & $\begin{array}{c}0.20 \sim \\
0.60\end{array}$ & $\begin{array}{c}1.20 \sim \\
1.60\end{array}$ & $\leq 0.020$ & $\leq 0.030$ & $\leq 0.30$ & $\leq 0.30$ \\
\hline 304 & $\leq 0.08$ & $\leq 1.00$ & $\leq 2.00$ & $\leq 0.05$ & $\leq 0.03$ & $\begin{array}{c}18.00 \sim \\
20.00\end{array}$ & $\begin{array}{c}8.0 \sim \\
10.50\end{array}$ \\
\hline
\end{tabular}

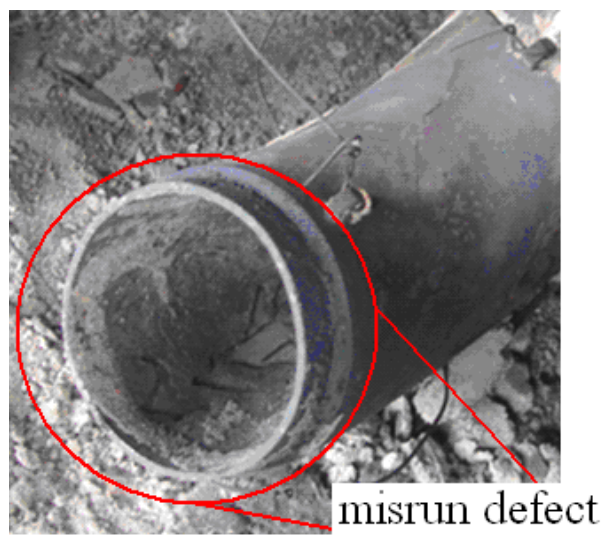

Figure 1. Real casting

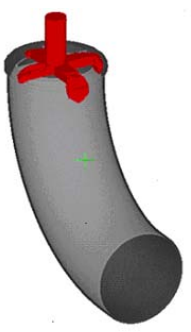

3s

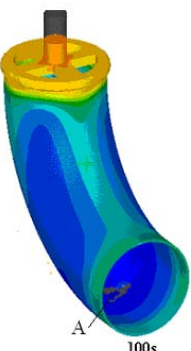

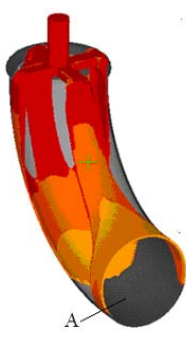

9s

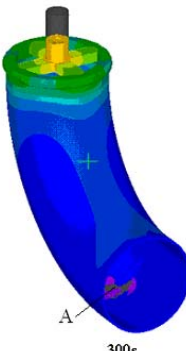

300 s

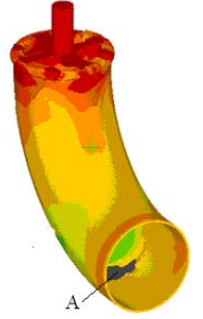

$17 \mathrm{~s}$

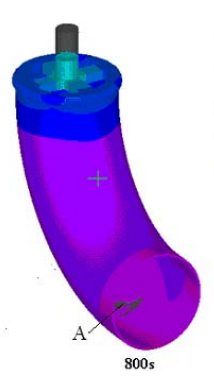

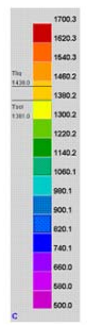

Figure 2. Temperature field distribution of the filling and solidification process of the bimetallic bending pipe

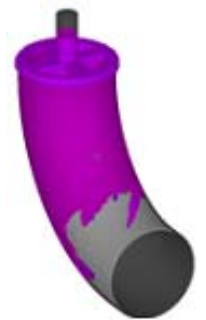

(a) $1600^{\circ} \mathrm{C}$

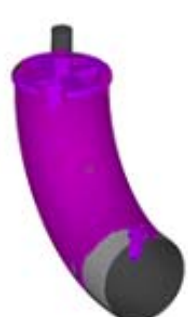

(b) $1650^{\circ} \mathrm{C}$

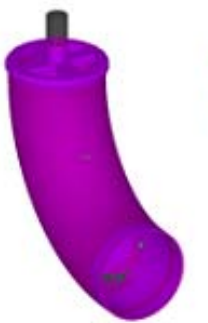

(c) $1700^{\circ} \mathrm{C}$

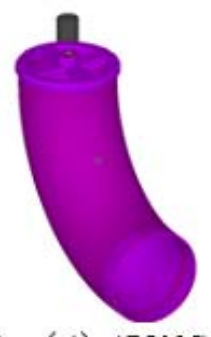

(d) $1750^{\circ} \mathrm{C}$

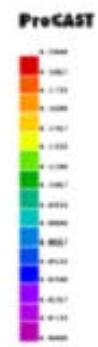

Figure 3. Distribution of shrinkage rate of a casting at different pouring temperatures 